\title{
Metallothionein-1 and nitric oxide expression are inversely correlated in a murine model of Chagas disease
}

\author{
Martha Elba Gonzalez-Mejia', Enrique Torres-Rasgado', Leonardo M Porchia², \\ Hilda Rosas Salgado², José-Luis Totolhua², Arturo Ortega ${ }^{3}$, Luisa Clara Regina Hernández-Kelly³, \\ Guadalupe Ruiz-Vivanco', Blanca G Báez-Duarte', Ricardo Pérez-Fuentes ${ }^{1,2}{ }^{1+}$
}

\author{
${ }^{1}$ Facultad de Medicina, Benemérita Universidad Autónoma de Puebla, Puebla, México ²Laboratorio de Fisiopatología \\ de Enfermedades Crónicas, Centro de Investigación Biomédica de Oriente, Instituto Mexicano del Seguro Social, Puebla, México \\ ${ }^{3}$ Departamento de Genética y Biología Molecular, Centro de Investigación y de Estudios Avanzados, Unidad Zacatenco, México DF, México
}

Chagas disease, caused by Trypanosoma cruzi, represents an endemic among Latin America countries. The participation of free radicals, especially nitric oxide (NO), has been demonstrated in the pathophysiology of seropositive individuals with T. cruzi. In Chagas disease, increased NO contributes to the development of cardiomyopathy and megacolon. Metallothioneins (MTS) are efficient free radicals scavengers of NO in vitro and in vivo. Here, we developed a murine model of the chronic phase of Chagas disease using endemic T. cruzi RyCHI in BALB/c mice, which were divided into four groups: infected non-treated (Inf), infected $N$-monomethyl-L-arginine treated (Inf L$N A M E)$, non-infected L-NAME treated and non-infected vehicle-treated. We determined blood parasitaemia and NO levels, the extent of parasite nests in tissues and liver MT-I expression levels. It was observed that NO levels were increasing in Inf mice in a time-dependent manner. Inf L-NAME mice had fewer $\mathrm{T}$. cruzi nests in cardiac and skeletal muscle with decreased blood NO levels at day 135 post infection. This affect was negatively correlated with an increase of MT-I expression ( $r=-0.8462, p<0.0001)$. In conclusion, we determined that in Chagas disease, an unknown inhibitory mechanism reduces MT-I expression, allowing augmented NO levels.

Key words: metallothionein-I - antioxidants - nitric oxide - L-NAME - Chagas disease

Chagas disease is one of the most imperative health problems in Latin America. It is caused by the protozoan parasite Trypanosoma cruzi (Rassi Jr et al. 2010, WHO 2013). In Mexico, several strains have been isolated. Interestingly, each strain presents with different tissue tropism and severity of the disease (Melo \& Brener 1978, de Lana et al. 2000, Gómez-Hernández et al. 2011).

Radical nitric oxide (NO) is a small molecule that has multiple biologic activities against parasite infections, such as schistosomiasis, leishmaniasis, toxoplasmosis and trypanosomiasis (James 1995). The dual role of NO during Chagas disease is currently being deduced. Some researchers have shown that NO levels increase during the acute phase of infection, inhibiting the progression of the disease by destroying the T. cruzi. Interestingly, the NO levels during the chronic phase have been shown to have adverse effects (Pérez-Fuentes et al. 2008, Rassi Jr et al. 2010). We have demonstrated that subjects infected with T. cruzi during chronic phase of Chagas disease presented with three times higher NO levels in their serum (Pérez-Fuentes et al. 1998, 2008). In addition, a

doi: 10.1590/0074-0276140339

Financial support: SIZA-CONACYT (19980802019)

MEG-M and ET-R were recipients of fellowships from CONACYT.

+Corresponding author: rycardoperez@hotmail.com

Received 26 June 2013

Accepted 5 February 2014 positive correlation was found between NO levels and disease severity during the chronic phase (Pérez-Fuentes et al. 2008), which was not seen during the acute phase of infection. The antimicrobial activity of cytokine-activated macrophages was decreased when they were treated with inducible NO synthase inhibitors, L-imino-ethylL-ornithine and N-monomethyl-L-arginine (L-NAME), which allowed parasite proliferation in vitro (Vespa et al. 1994, Fichera et al. 2004). This data supports the notion that NO levels will limit local inflammation caused by the parasite during the acute phase. However, during the chronic phase of Chagas disease, there is an increase in free radicals that contributes to enhanced oxidative stress and organ damage in patients.

Metallothioneins (MTs), a low-molecular weight protein (Vasak \& Meloni 2011), protect the cells from a variety of reactive oxidants species, such as hydrogen peroxide and hydroxyl radical, by acting as an antioxidant and a radical scavenger (Viarengo et al. 2000, Petering et al. 2009, Vasak \& Meloni 2011). MTs are expressed in various organs/tissues and their expression levels can be augmented by inflammatory stimuli, making them an anti-inflammatory mediator (Inoue et al. 2009). There are four MTs genes (I-IV) (Thirumoorthy et al. 2011). MT-I and MT-II are expressed in various tissues, most notably the liver and kidney. MT-III is mainly found in the brain, whereas MT-IV is expressed primarily in stratified squamous epithelia cells (Thirumoorthy et al. 2011). Evaluation of MTs' protective role showed an increased expression against different aetiologies of oxidative stress, especially in liver tissue (Stankovic et al. 
2003, Kang 2006, Majumder et al. 2010). MT knockout mice also support the role of these proteins as essential antioxidants during oxidative stress (Molinero et al. 1998). Moreover, by using a restraint stress-induced rat model, the increased stress induced liver MT-I antioxidant activity by increasing MT-I levels in vivo, as determined by elevated liver MT-I mRNA and protein levels (Hernández et al. 2000). The role of MTs against reactive oxygen species and reactive nitrogen species, having a superior efficiency than superoxide dismutase (SOD) and glutathione (GSH), has been widely documented (Thornalley \& Vasak 1985, Inoue et al. 2009, Chen et al. 2012). However, the role of liver MT-I in the chronic phase of Chagas disease has not been evaluated.

During the chronic phase of Chagas disease, the production of pro-inflammatory cytokines led to a chronic inflammation, a reduction in antioxidant enzymes SOD and GSH and oxidative stress characterised by high levels of NO in the serum of patients (Pérez-Fuentes et al. 2008). One of MT's functions is to protect against oxidising agents. Since MTs are antioxidants and their expression has been related to infection and inflammation, it seems suitable to consider the possibility that there is a relationship between NO and MT regulation. The present study is aimed to evaluate the expression of MT-I and its relationship with NO blood serum levels and the effect of L-NAME treatment in a murine model of chronic Chagas using the T. cruzi RyCH1 isolated from Puebla, Mexico.

\section{MATERIALS AND METHODS}

Strain - The strain was isolated during epidemiological studies in Puebla. Parasites were genetically characterised as HUM/ME/1997/MEX/RyCH1 or as T. cruzi RyCH1 (Sánchez-Guillén et al. 2006). Isolates were routinely maintained by intraperitoneal (i.p.) passages in 10week-old BALB/c mice at four-week intervals.

Mice, infection and treatments - BALB/c female mice (8-10 weeks of age and $25 \pm 5 \mathrm{~g}$ ) were allocated at room temperature $\left(21-23^{\circ} \mathrm{C}\right)$. They received water and a commercial diet ad libitum (Alimento Balanceado de la Cienega, SA CV). Mice were obtained and maintained in animal facilities from East Biomedical Research Centre/Mexican Institute of Social Security (Puebla, MX) in compliance with the guidelines Official Mexican Norm NOM-062-ZOO-1999: Technical Specifications for the Production, Care and Use of Laboratory Animals (de Aluja 2002), as well as the International Guiding Principles for Biomedical Research involving animals (CIOMS/ICLAS 2012). The mice were randomly divided into four groups: infected non-treated $(\mathrm{Inf})(\mathrm{n}=$ $36)$, infected L-NAME treated (Inf L-NAME) $(\mathrm{n}=36)$, non-infected L-NAME treated (Non-Inf L-NAME) ( $\mathrm{n}=$ 36) and non-infected vehicle-treated (Non-Inf Veh) ( $\mathrm{n}=$ 36). Inf and Inf L-NAME were inoculated i.p. with $1 \mathrm{x}$ $10^{4}$ trypomastigotes of $T$. cruzi RyCH1 in $50 \mu \mathrm{L}$ of $4 \%$ sterile sodium citrate on days 0,30 and 60 . Inf L-NAME and Non-Inf L-NAME were treated with $25 \mathrm{mg} / \mathrm{Kg}$ of LNAME (N-nitro-L-arginine methyl ester hydrochloride, Cat: N575, St. Louis, MO) administered by i.p. injections once a week from days 0 through 195. Non-Inf Veh were not infected with T. cruzi RyCH1, yet received i.p. in- jection of diluents (100 $\mu \mathrm{L}$ sodium citrate $4 \%$ ). Blood parasitaemia was determined by cutting $1 \mathrm{~mm}$ off of the tail tip, followed by counting the number of parasites per $\mathrm{mL}$ of blood using a haemocytometer (Hart et al. 1981). Additionally, trypomastigotes forms where classify as thin form (small and immature) or thick form (large and mature) according to the specifications of the previously establish ratio method (width/length: w/l) (Martins et al. 2008). The mice were euthanised by cervical dislocation (4 mice from each group) after the last bleeding. Tissue samples were collected for an immediate histopathology analysis and liver tissue was isolated and stored at $-70^{\circ} \mathrm{C}$ until further use.

Histopathological analyses - Samples from the heart, skeletal muscle and the large intestine were fixed in 10\% formaldehyde, dehydrated in absolute alcohol and then embedded in paraffin. For each organ, serial sections of $5 \mu \mathrm{m}$ were cut in a microtome. Tissue samples were stained with haematoxylin and eosin (H\&E) and then examined by light microscopy using a Zeiss microscope (Carl Zeiss AG, Oberkochen, Germany). Photographs were taken at the indicated magnification with an Olympus X-785 digital camera coupled to the microscope. For T. cruzi nests analysis, mice were sacrificed at two and three weeks post-infection (p.i.) and their organs were analysed using H\&E staining (heart, diaphragm, oesophagus, colon and skeletal muscle), followed by quantification of amastigote nests and inflammatory infiltrates (more than 10 mononuclear cells) in 100 fields at $100 \mathrm{X}$ magnification.

Measuring the serum levels of $\mathrm{NO}$ - The NO levels were evaluated by measuring the nitrite $\left(\mathrm{NO}_{2}-\right)$ level in serum samples using the Griess reaction (Green et al. 1982, Nithipatikom et al. 1996). Nitrate was reduced to $\mathrm{NO}_{2}$ - using spongy cadmium (5-20-mesh, Sigma). Sodium nitrite $\left(\mathrm{NaNO}_{2}\right)$ was used to make a standard curve. Sodium nitrate $\left(\mathrm{NaNO}_{3}\right)$ was used as a standard and to determine reaction efficiency. The overall reaction can be described as following: $\mathrm{NO}_{3}-\mathrm{H}_{2} \mathrm{O}+\mathrm{Cd} \rightarrow \mathrm{NO}_{2^{-}}+$ $\mathrm{Cd}^{2}++2 \mathrm{OH}^{-}$. The absorbency was measured at $540 \mathrm{~nm}$ in a microplate ELISA reader (Multiskan MS, Labsystems OY, Helsinki, Finland).

Quantitative reverse-transcriptase polymerase chain reaction ( $q R T-P C R$ ) - Liver samples were homogenised with a Polytron Willems (PT10/35) homogeniser (Brinkmann Instruments, Westbury, NY, USA) in $1 \mathrm{~mL}$ of TRI$\mathrm{zol}^{\circledR}$ (Invitrogen, Grand Island, NY, USA) to $100 \mathrm{mg}$ of liver tissue. The RNA was extracted according to manufacturer's protocol. The cDNA was synthesised using 4 $\mu \mathrm{g}$ of total RNA from liver tissue with $10 \mathrm{U}$ of MMLV reverse transcriptase (Gibco BRL), $2 \mu \mathrm{L}$ of $10 \mathrm{X}$ buffer without $\mathrm{Mg}^{2}+, 10 \mathrm{mM}$ dNTPs stock solution $[2.5 \mathrm{mM}$ each of dA, dG, dC and dT (Strategene)], $50 \mathrm{mM} \mathrm{MgCl}$ (Gibco BRL), $10 \mathrm{mM}$ oligo-d(T) (Gibco BRL), 5 U ribonuclease inhibitor (Gibco BRL) and $10 \mathrm{mM}$ DTT (Gibco $\mathrm{BRL}$ ) in $20 \mu \mathrm{L}$ final volume, followed by incubation for $1 \mathrm{~h}$ at $37^{\circ} \mathrm{C}$. Primers were synthesised according to an alignment of the amino acid and nucleotide sequences reported for wild type MT-I mice (Mbikay et al. 1981), sequences MT-I (Fwd):TCCCGAGCATTACTAAA and 
MT-I (Rev): ACCCCAGTTTCTTATTG. PCR reactions were synthesised using $6 \mu \mathrm{L}$ of cDNA reaction $(6 \mu \mathrm{g})$, 2.5 U Taq DNA polymerase (Gibco BRL), $8 \mu \mathrm{L}$ of $10 \mathrm{X}$ buffer without $\mathrm{Mg}^{2}+$ (Gibco BRL), $10 \mathrm{mM}$ dNTPs stock solution $[2.5 \mathrm{mM}$ each of $\mathrm{dA}, \mathrm{dG}, \mathrm{dC}$ and $\mathrm{dT}$ (Strategene)], $50 \mathrm{mM} \mathrm{MgCl}$ (Gibco BRL), 20 pmol of each MT-I primers, 0.8 pmol of each G3PDH primers [G3PDH (Fwd): TGAAGGTCGGTGTGAACGGATTTGGC and G3PDH (Rev): CATGTAGGCCATGAGGTCCAC$\mathrm{CAC}]$ in $80 \mu \mathrm{L}$ final volume. MT-I and G3PDH were amplified simultaneously in PTC-100 Thermal Cycler (MJ Research, Alameda, CA, USA) for 35 cycles $\left(94^{\circ} \mathrm{C}\right.$ for 1 $\min , 54^{\circ} \mathrm{C}$ for $1 \mathrm{~min}$ and $72^{\circ} \mathrm{C}$ for $1 \mathrm{~min}$ ). PCR products were separated with a $1.5 \%$ agarose gel and visualised with $1 \%$ ethidium bromide. MT-I copy numbers were divided by G3PDH (housekeeping gene) to standardise the data set.

Statistical analysis - Data is expressed as the mean (average) \pm standard error. A two-way ANOVA was performed to determine significant differences between the groups. When this analysis indicated a significance of more than $5 \%$, a post hoc Student-Newman-Keuls analysis was used to determine which groups significantly differed. The data was analysed and graphed using GraphPad PRISM v.5 software (San Diego, CA, USA).

\section{RESULTS}

Parasitaemia levels of T. cruzi RyCH1 forms $\mathrm{BALB} / \mathrm{c}$ mice that were inoculated i.p. with 1 x $10^{4}$ trypomastigotes $T$. cruzi RyCH1 on days 0,30 and 60 resulted in a development of the chronic phase of Chagas disease in Inf and Inf L-NAME groups. To comprehend the role of $\mathrm{NO}$ in the chronic phase of infection in vivo, L-NAME treatment was administrated by i.p injection $(25 \mathrm{mg} / \mathrm{Kg})$ once a week since day 0 (4 h p.i.) (Vespa et al. 1994, James 1995) for the Inf L-NAME and Non-Inf L-NAME groups. Parasitaemia levels were determined in the infected groups (Inf and Inf L-NAME) by microscopic examination of tail vein blood every three days for two months. After two months, they were examined every 15 days, until day 195. The Inf group presented thin forms of the T. cruzi RyCH1 parasite on day 6 and then became undetectable after day 12 . The thick forms of $T$. cruzi RyCH1 were detectable on day 6 , with a peak of parasitaemia $\left[0.45 \times 10^{6}\right.$ parasites blood forms $/ \mathrm{mL}$ (PBF/mL)] on day 27 (Table I). After day 42, the infection started to shift from the acute phase to the chronic phase, during which PBF became undetectable under microscopic examination (Table I). Interestingly, L-NAME promoted the earlier presence of thin forms of T. cruzi $\mathrm{RyCH} 1$ on day 3 and the thick forms on day 6 , with a

TABLE I

Parasitaemia levels of Trypanosoma cruzi RyCH1 forms in infected non-treated (Inf) and infected N-monomethyl-L-arginine treated (Inf L-NAME) infected mice

\begin{tabular}{|c|c|c|c|c|c|c|}
\hline \multirow[b]{2}{*}{ Day } & \multicolumn{3}{|c|}{ Inf } & \multicolumn{3}{|c|}{ Inf L-NAME } \\
\hline & $\begin{array}{l}\text { Thin } \\
\text { forms }\end{array}$ & $\begin{array}{l}\text { Thick } \\
\text { forms }\end{array}$ & Total $/ \mathrm{mL}$ & $\begin{array}{l}\text { Thin } \\
\text { forms }\end{array}$ & $\begin{array}{l}\text { Thick } \\
\text { forms }\end{array}$ & Total $/ \mathrm{mL}$ \\
\hline 0 & - & - & - & - & - & - \\
\hline 3 & - & - & - & $0.06 \pm 0.24$ & - & $0.06 \pm 0.24$ \\
\hline 6 & $1.45 \pm 0.29$ & $0.07 \pm 0.01$ & $1.53 \pm 0.31$ & $1.83 \pm 0.22$ & $0.08 \pm 0.02$ & $1.91 \pm 0.24$ \\
\hline 9 & $1.14 \pm 0.25$ & $1.40 \pm 0.31$ & $2.55 \pm 0.56$ & $1.34 \pm 0.43$ & $2.48 \pm 0.67$ & $3.82 \pm 0.70$ \\
\hline 12 & $0.95 \pm 0.09$ & $3.82 \pm 0.39$ & $4.78 \pm 0.49$ & $0.14 \pm 0.08$ & $4.96 \pm 0.62$ & $5.10 \pm 0.65$ \\
\hline 15 & - & $6.37 \pm 0.57$ & $6.37 \pm 0.57$ & - & $7.73 \pm 0.72$ & $7.73 \pm 0.72$ \\
\hline 18 & - & $9.45 \pm 0.23$ & $9.45 \pm 0.23$ & - & $6.70 \pm 0.47$ & $6.70 \pm 0.47$ \\
\hline 21 & - & $16.22 \pm 1.43$ & $16.22 \pm 1.43$ & - & $15.20 \pm 0.51$ & $15.20 \pm 0.51$ \\
\hline 24 & - & $29.16 \pm 4.43$ & $29.16 \pm 4.43$ & - & $19.80 \pm 0.98$ & $19.80 \pm 0.98$ \\
\hline 27 & - & $45.77 \pm 3.94$ & $45.77 \pm 3.94$ & - & $36.93 \pm 4.30$ & $36.93 \pm 4.30$ \\
\hline 30 & - & $19.16 \pm 0.31$ & $19.16 \pm 0.31$ & - & $54.53 \pm 3.18$ & $54.53 \pm 3.18$ \\
\hline 33 & - & $9.66 \pm 0.60$ & $9.66 \pm 0.60$ & - & $27.10 \pm 1.64$ & $27.10 \pm 1.64$ \\
\hline 36 & - & $4.44 \pm 0.37$ & $4.44 \pm 0.37$ & - & $10.60 \pm 0.93$ & $10.60 \pm 0.93$ \\
\hline 39 & - & $1.78 \pm 0.16$ & $1.78 \pm 0.16$ & - & $2.53 \pm 0.44$ & $2.53 \pm 0.44$ \\
\hline 42 & - & $0.16 \pm 0.047$ & $0.16 \pm 0.047$ & - & $1.80 \pm 0.032$ & $1.80 \pm 0.032$ \\
\hline 45 & - & - & - & - & $0.53 \pm 0.18$ & $0.53 \pm 0.18$ \\
\hline $60-195$ & - & - & - & - & - & - \\
\hline
\end{tabular}

BALB/c mice were inoculated with 1 x $10^{4}$ blood trypomastigotes of HUM/ME/1997/MEX/RyCH1 or T. cruzi RyCH1 on days 0,30 and 60 in the Inf and Inf L-NAME groups. Treatment with L-NAME was administered with a $25 \mu \mathrm{g} / \mathrm{Kg}$ intraperitoneal injection once a week for Inf L-NAME, beginning on day 0 ( $4 \mathrm{~h}$ post-infection). Parasitaemia peaks are shown in bold. The values represent parasite blood forms $\times 10^{4} / \mathrm{mL}$. 
peak of parasitaemia on day 30 , which was significantly higher than the $\operatorname{Inf}\left(0.54 \times 10^{6} \mathrm{PBF} / \mathrm{mL}, \mathrm{p}<0.05\right)$ (Table I). In addition, with L-NAME treatment, blood parasitaemia were detectable until day 45 (Table I). Therefore, these data suggest L-NAME treatment, which causes a decrease in NO levels, is associated with an earlier detection of thin forms of T. cruzi RyCH1 and had a larger peak of parasitaemia at a later time.

Compartmental alteration and histopathological analysis of T. cruzi RyCH1 - Clinical manifestations of the chronic phase of Chagas disease [slight alterations in fur colour (yellowish) with piloerection, especially in the dorsal region, hunched posture and decrease activity-level] were observed at day 75 in Inf and Inf LNAME mice and showed minimal physical differences when compare with previously reported mice models (Vespa et al. 1994, James 1995). Non-Inf L-NAME and Non-Inf Veh mice presented with healthy physical and clinical characteristics (displayed with a white brilliant fur, showed no signs of peeling and were physically active) and did not manifest any side-effects related to the administration of either L-NAME or diluents controls, respectively. After day 135, Inf mice showed severe paralysis of the lower extremities when compared with Inf L-NAME mice (Supplementary data).

Histopathological analysis showed the presence of parasite nests in Inf mice starting at day 15 in skeletal muscle and heart tissues. As the time progressed, the maximum number of parasite nests was found to be in heart tissue followed by skeletal muscle on day 27 ( $p<$ 0.01 ), with no significant presences in the diaphragm (Table II). This data correlates with the Inf group's peak of parasitaemia (day 27) (Table I). The Inf L-NAME group showed a similar tissue preference profile, with heart and muscle tissue having a significantly greater expression than other examined tissues (day 21, $\mathrm{p}<0.01$ ). Interestingly, at the time for the peak of parasitaemia (day 30), the amount of nest is considerably fewer than day 21 (Table II). Furthermore, the L-NAME caused a reduced amount of nests in heart and muscle tissue (after day 27 and during the chronic phase) (Table II). In addition with the L-NAME treatment, we were able to detect nests in other tissues: colon, diaphragm and oesophagus (day 21) (Table II). Therefore, it seems that L-NAME allows the establishment of nests in multiple tissues, but counteracts the severity of the invasion.

To assess the severity of the invasion, we examined the heart and skeletal muscle tissue at day 135 p.i. The extensiveness of nest formation were examined by H\&E staining of heart muscle (Fig. 1A, C) and skeletal muscle (Fig. 1B, D). We were able to view the presence of amastigote nests which were surrounded by lymphocytes infiltrate (Fig. 1). Planes corresponding to the Inf group had an average of $7 \pm 4$ nest per a field, whereas the Inf L-NAME group had a significant lower amount $(1.4 \pm$ 1.2 nest per a field, $\mathrm{p}<0.01$ ) for the heart (Fig. 1A, C). These results were similar for the skeletal muscle $(3 \pm$ 2.2 vs. $1.6 \pm 0.57$ for Inf and Inf L-NAME, respectively, $\mathrm{p}<0.01$ ) (Fig. 1B, D). Therefore, these results suggest that L-NAME affects the development of nests during the chronic phase by an unknown mechanism.
NO levels of T. cruzi RyCH1 in Inf and the effected of L-NAME treatment - We have demonstrated that NO levels are higher in patients with the chronic phase of Chagas disease (Pérez-Fuentes et al. 2008). Therefore, the NO levels were determined in all of the groups using the Griess technique (Green et al. 1982). The Inf group showed a progressive increase in NO levels, which reached a maximum value of $27.30 \mu \mathrm{mol} / \mathrm{mL}$ after day 165 (Fig. 2A). This was significantly higher than the non-infected mice (Non-Inf L-NAME and Non-Inf Veh, $p<0.001)$. The Inf L-NAME group also showed an increase in NO levels, peaking at day 75 , which was also significantly higher than the Inf group $(15 \mu \mathrm{mol} / \mathrm{mL}$ vs. $12.5 \mu \mathrm{mol} / \mathrm{mL}, \mathrm{p}<0.05)$. However, after day 75 , the NO levels decreased and returned to basal levels (similar to Non-Inf L-NAME and Non-Inf Veh) by day 195 (Fig. $2 \mathrm{~A})$. This result was significantly lower than $\operatorname{Inf}(\mathrm{p}<$ 0.001 ). These data suggest that L-NAME, at $25 \mathrm{mg} / \mathrm{Kg}$, did not block NO levels during the acute phase, allowing the development of the chronic phase of Chagas disease. Afterward, the NO levels decreased significantly, thereby preventing damage that is normally caused by NO during the chronic phase.

\section{TABLE II}

Preferential tissue growth/survival of Trypanosoma cruzi RyCH1 in infected non-treated (Inf) and infected N-monomethyl-L-arginine treated (Inf L-NAME) groups

\begin{tabular}{|c|c|c|c|c|}
\hline \multirow{2}{*}{$\begin{array}{l}\text { Group } \\
\text { Day p.i. }\end{array}$} & \multicolumn{4}{|c|}{ Inf } \\
\hline & 15 & 21 & 27 & 33 \\
\hline Muscle & $4.0 \pm 2.5$ & $19.5 \pm 5.6^{a}$ & $24.6 \pm 8.0^{b}$ & $7.0 \pm 4.7$ \\
\hline Heart & $2.0 \pm 0.8$ & $18.5 \pm 3.5^{a}$ & $60.5 \pm 20.2^{b}$ & $11.2 \pm 5.8$ \\
\hline Diaphragm & - & - & $1.4 \pm 1.0$ & - \\
\hline Colon & - & - & - & - \\
\hline Oesophagus & - & - & - & - \\
\hline Group & \multicolumn{4}{|c|}{ Inf L-NAME } \\
\hline Day p.i. & 15 & 21 & 27 & 33 \\
\hline Muscle & $17.5 \pm 9.2$ & $30.5 \pm 15.1^{b}$ & $14.8 \pm 6.9$ & $1.6 \pm 0.6$ \\
\hline Heart & $4.0 \pm 3.4$ & $28.8 \pm 11.2^{b}$ & $11.8 \pm 2.8$ & $1.4 \pm 1.2$ \\
\hline Diaphragm & - & $2.0 \pm 1.4$ & - & - \\
\hline Colon & $1.2 \pm 0.8$ & $1.0 \pm 0.6$ & - & - \\
\hline Oesophagus & - & $1.0 \pm 0.7$ & - & - \\
\hline
\end{tabular}

$a: \mathrm{p}<0.05 ; b: \mathrm{p}<0.001$. BALB/c mice were inoculated with 1 x $10^{4}$ blood trypomastigotes of HUM/ME/1997/MEX/RyCH1 or T. cruzi RyCH1 on days 0, 30 and 60 in the Inf and Inf LNAME groups. Treatment with L-NAME was administered with a $25 \mu \mathrm{g} / \mathrm{Kg}$ intraperitoneal injection once a week for LNAME, beginning on day 0 . Number of parasite nests in tissue sample was determinate with haematoxylin and eosin staining at the indicated day. p.i.: post-infection. 
Liver levels of MT-I in T. cruzi RyCH1 - One protein of interest that can regulate NO levels is MT-I; therefore, the expression of MT-I was assessed in the murine model during the chronic phase. The mice were sacrificed at day 3, 15, 45 and then every 30 days. The liver RNA was collected and MT-I levels were determined using semiqRT-PCR. The MT-I gene expression was significantly higher during the acute phase in the Inf group (Fig. 2B) $(\mathrm{p}<0.001)$; however, the MT-I levels decreased significantly as the time of infection prolonged $(p<0.001)$. Whereas in the control groups (Non-Inf Veh and NonInf L-NAME), the MT-I expression levels presented no significant difference and remained constant. With the Inf L-NAME group, the MT-I expression significantly increased in a time-dependent manner with a maximum peak of expression at day 165 . This peak was a 2.7 -fold higher than the Inf group $(\mathrm{p}<0.001)$ (Fig. 2B). These data suggest that MT-I levels increased with the treatment of L-NAME during the chronic phase.

Correlation of MT-I and NO during the chronic phase of Chagas disease - MT production has been shown to increase in organisms exposed to high levels of reactive oxygen and nitrogen species (Miles et al. 2000). However, we observed an inverse correlation between the levels of MT-I and NO (Fig. 3). While NO levels remained continuously high during the chronic phase (Fig. 2A, open circle), MT-I levels showed a decrease in expression (Fig. 2B, open circle). Using these data, we determined an inverse correlation between NO levels and MT-I expression (Fig. 3A) $(\mathrm{r}=-0.8462, \mathrm{p}<0.0001)$. The same inverse correlation was evident when $\mathrm{NO}$ levels were inhibited by L-NAME (Fig. 3B) $(r=-0.7480 \mathrm{p}<$ 0.001 ), which decreased the levels of NO (Fig. 2A, open boxes) and increased the levels of MT-I (Fig. 2B, open

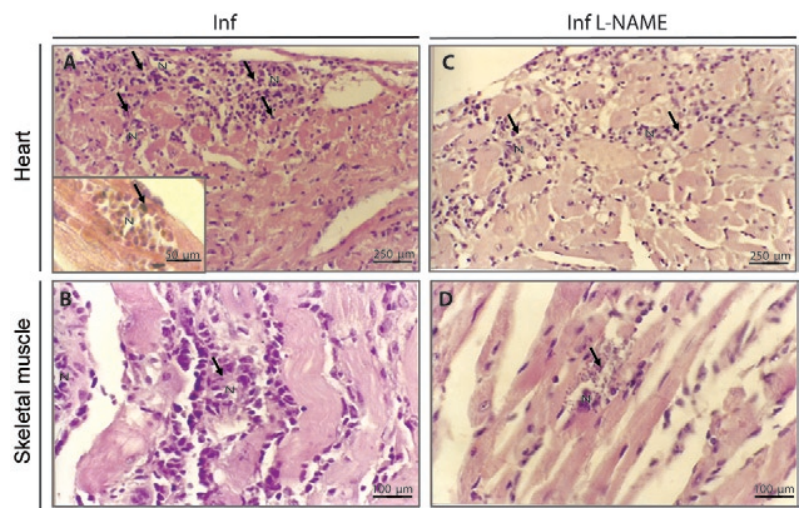

Fig. 1: histopathological changes in heart and skeletal muscle of Trypanosoma cruzi RyCH1 in infected non-treated (Inf) and infected $\mathrm{N}$-monomethyl-L-arginine treated (Inf L-NAME) groups. BALB/c mice were infected with $1 \times 10^{4}$ blood trypomastigotes of $T$. cruzi RyCH1. L-NAME was administered $25 \mu \mathrm{g} / \mathrm{Kg}$ intraperitoneally. Tissue samples were stained with haematoxylin and eosin and then examined by light microscope at 135 days post-infection. Lesions are representative of at least four animals in each group. Infiltrate inflammatory tissues are indicated by arrows. Bar indicates specific $\mu \mathrm{m}$ size. N: nest. boxes). Therefore, during the chronic phase of Chagas disease, an inverse correlation between the levels of NO and MT-I was observed.

\section{DISCUSSION}

Virulence, infectivity and pathogenesis of T. cruzi are mediated by the strain (Marinho et al. 2009, Espinoza et al. 2010). With Chagas disease, regional strain analysis is necessary for the development of targeted treatment options. The state of Puebla has an incidence rate of $7.7 \%$, with the predominance in cardiac alterations (SánchezGuillén et al. 2006). Our results have demonstrated that the HUM/ME/1997/MEX/RyCH1 (T. cruzi RyCH1) strain, using BALB/c mice as the host, was able to develop pathological and clinical characteristics of Chagas disease. This allowed us to analyse the chronic phase of the disease as observed in the population of Puebla. In our murine model, the physical changes correspond-
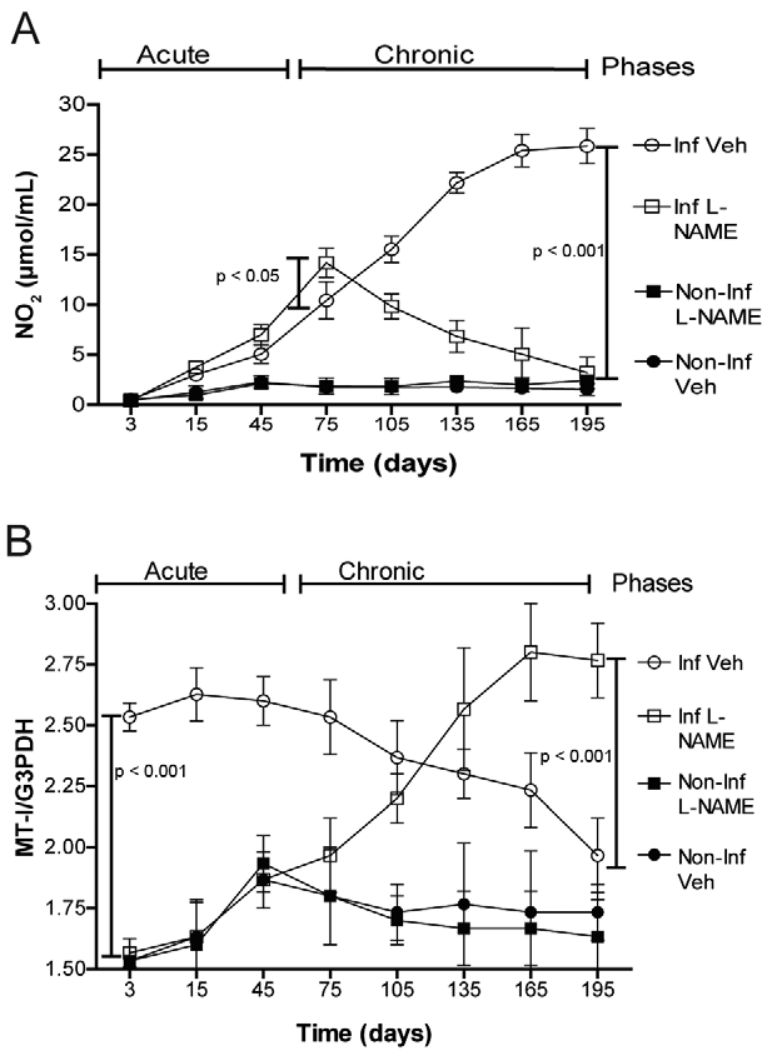

Fig. 2: time course of nitric oxide (NO) and metallothionein-1 (MT-I) levels in the liver of Trypanosoma cruzi RyCH1 in infected non-treated (Inf) and the effected of N-monomethyl-L-arginine (L-NAME) treatment. Inf and Inf L-NAME were intraperitoneally inoculated with $1 \times 10^{4}$ blood trypomastigotes of T. cruzi RyCH1 on day 0,30 and 60. Inf L-NAME and non-infected L-NAME treated (Non-Inf LNAME) received L-NAME once a week $(25 \mathrm{mg} / \mathrm{kg})$. Blood and liver RNA was collected from each group on day 3,15 and 45 , then every 30 days. A: NO levels determined by the Griess method; B: MT-I and $G 3 P D H$ gene expression determined by semi-quantitative polymerase chain reaction. Results are mean \pm standard error $(n=4)$. Data was normalised with expression levels of G3PDH. Non-Inf Veh: noninfected vehicle-treated. 
ing to the chronic phase appeared after day 45 , which correlated with absence of circulating parasites. These physical characteristics are consistent with other murine models, featuring alterations in fur colour with piloerection, hunched posture and severe paralysis of the lower extremities (da Silva et al. 2012). Kinetics of parasitaemia in this model also showed similar levels to other wellstudied strains in chronic phase (Table I), such as T. cruzi Tulahuén, 21SF, Mambai, Bolivia, TBAR/MX/0000/ Queretaro and MHOM/MX/1994/Ninoa (Andrade \& Grimaud 1986, Petray et al. 1995, Espinoza et al. 2010). Therefore, we are led to conclude that our model is physically similar to other murine models of Chagas disease. In addition, parasitaemia levels for both groups were undetectable, as seen previously with other $T$. cruzi strains during the chronic phase (Espinoza et al. 2010, Guedes et al. 2010). Moreover, the preferential tissue growth study demonstrated that during the acute phase, L-NAME did significantly alter the severity of the infection, allowed

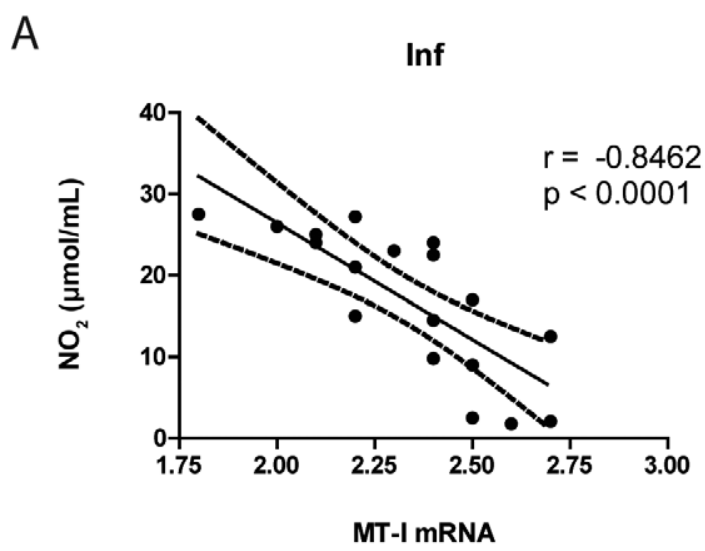

B

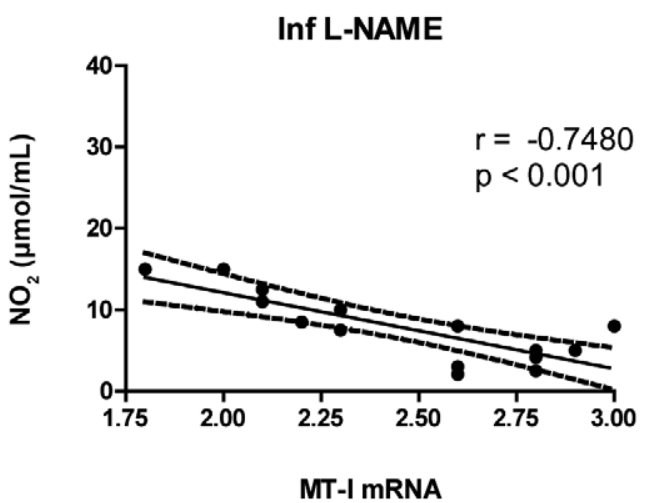

Fig. 3: Spearman's correlations between blood nitric oxide (NO) and liver metallothionein-1 (MT-I) levels during chronic phase of Chagas disease. BALB/c mice were inoculated with $1 \times 10^{4}$ blood trypomastigotes of Trypanosoma cruzi RyCH1 on day 0, 30 and 60 (Inf and Inf L-NAME). L-NAME was administered once weekly at $25 \mathrm{mg} / \mathrm{kg}$ [infected non-treated (Inf) and infected N-monomethyl-L-arginine treated (Inf L-NAME)]. Blood and liver RNA samples were collected on day 3,15 and 45 , then every 30 days. NO and MT-I level were determined by semi-quantitative reverse-transcriptase polymerase chain reaction. Sperman's correlation was determinate using Graph Pad PRISM v. 5 software. infection to progress in organs in which parasitism is usually low/undetectable (Table II). The levels of parasitism in these organs, when compared to other strains, were unique for this strain (Guarner et al. 2001).

Normally, NO is required by the immune system to eradicate the parasite during the acute phase of the infection. If NO levels decrease, then augmented parasitaemia will eventually lead to the death of the murine host (Vespa et al. 1994, James 1995). Treatment with NO inhibitors resulted in an increase in parasitaemia and mortality during the acute phase (Petray et al. 1995, Jacobs et al. 1996, 1998, Millar \& Kahn 2000). However, it is still not clear what effect elevated blood NO levels has on patients with the chronic phase of Chagas disease. L-NAME, a NO inhibitor, was administrated once a week between day 0 ( $4 \mathrm{~h}$ p.i.) to the end of experiment, at a dose of $25 \mathrm{mg} / \mathrm{Kg} / \mathrm{week}$. This diverges from other published treatments and doses. Other groups ordinarily treated with $\sim 5 \mathrm{mg} / \mathrm{Kg}$ per/day, which corresponds to between 25-35 mg/kg each week (Petray et al. 1995, Jacobs et al. 1996, Millar \& Kahn 2000). This dose of 25 $\mathrm{mg} / \mathrm{kg} /$ week allowed mice to survive the acute phase of infection and develop the chronic phase of Chagas disease without decreasing their survival rate. In contrast, most mice treated with $5 \mathrm{mg} / \mathrm{Kg}$ /day developed a severe acute phase, which eventually led to a high parasite burden and death (Petray et al. 1995, Jacobs et al. 1996, Millar \& Kahn 2000).

When the mice were treated with L-NAME at 25 $\mathrm{mg} / \mathrm{kg} /$ week (Inf L-NAME), two notable effects on NO levels were observed. NO levels increased during the acute phase with no significant variation until day $75(\mathrm{p}<0.05)$ (Fig. 3). Our purposed explanation is that the administration of L-NAME at $4 \mathrm{~h}$ p.i affected the NO production during the first few days of the infection. This allowed the parasite to propagate quickly in blood, as demonstrated by the presence of the thin/immature forms of T. cruzi at an earlier timeframe (Table I). The reason for the earlier detection of the thin/immature forms we are currently examining. We speculate that the increases of the thick/mature forms in blood are due to a block in tissue tropism. We were able to see a decrease of nest in L-NAME treated mice after day 27 (Table II) and day 135 (Fig. 1C, D). The second notable affect was, at the initiation of the chronic phase ( $>$ day 75), NO levels decreased significantly in Inf L-NAME mice due to the L-NAME treatment $(\mathrm{p}<0.001)$. This correlated with the undetectable parasitaemia levels and the lower nest present in tissues. In addition, it also correlated with the significantly higher levels of MT-I.

Many researchers have demonstrated that the trypomastigotes of $T$. cruzi are cleared by the liver (Umekita et al. 1998, Müller et al. 2003, Sardinha et al. 2010). During inflammation, toxin insults and oxidative stress damage caused increased expression of MTs in the liver (Stankovic et al. 2003, Park et al. 2011). Although published results suggest that an elevation in NO levels will lead to an elevation in MT-I levels as a protective mechanism (Arizono et al. 1995, Hernández et al. 2000, Katakai et al. 2001, Kruczek et al. 2011, Chen et al. 2012), our results demonstrate the contrary. When we evaluated the 
MT-I levels during the chronic phase of Chagas disease, the Inf group demonstrated a reduced MT-I level when the NO level was elevated (Fig. 2A). However, with the L-NAME treated mice, when the NO level was low, the MT-I level was high (Fig. 2B). A correlation analysis determined that this was a strong inverse relationship (Fig. 3). The mechanism for this inverse relationship is currently unknown. We suggest that the chronic inflammation caused by Chagas disease, which is signified by high levels of NO, may led to a down regulation of MT-I. This is in agreement with the clinical data (Pérez-Fuentes et al. 2003, 2007). Inflammatory cytokines tumour necrosis factor-alpha and interleukin- 6 have been shown to regulate MTs family proteins (Liu et al. 1991, Kim et al. 2005, Kobayashi et al. 2005). Therefore, during the chronic phase of Chagas disease, we suggest that MT-I could be down-regulated by these pro-inflammatory cytokines. It will be crucial to further investigate and characterise the mechanism involved in the inhibition of MT-I during the chronic phase of Chagas disease.

\section{ACKNOWLEDGEMENTS}

To Luis Angel Cid Cid and Blanca Ibarra, from CINVESTAV-IPN, for technical assistance, to Alfredo Avendaño Arenaza and Ricardo Villegas Tovar, from Libraries Department at BUAP, to the memory of Dr Maria del Carmen Sanchez-Guillen, our mentor and friend who started the project, and to Susannah Leigh Pearce, for linguistical editing of this paper.

\section{REFERENCES}

Andrade SG, Grimaud JA 1986. Chronic murine myocarditis due to Trypanosoma cruzi - an ultrastructural study and immunochemical characterization of cardiac interstitial matrix. Mem Inst Oswaldo Cruz 81: 29-41.

Arizono K, Kagawa S, Hamada H, Ariyoshi T 1995. Nitric oxide mediated metallothionein induction by lipopolysaccharide. Res Commun Mol Pathol Pharmacol 90: 49-58.

Chen Z, Li J, Zhao TJ, Li XH, Meng FG, Mu H, Yan YB, Zhou HM 2012. Metallothioneins protect cytosolic creatine kinases against stress induced by nitrogen-based oxidants. Biochem J 441: 623632 .

CIOMS/ICLAS - Council for International Organization of Medical Sciences/International Council for Laboratory Animal Science 2012. International guiding principles for biomedical research involving animals. Available from: cioms.ch/.

da Silva DR, de Castro SL, Alves MCS, Batista WS, de Oliveira GM 2012. Acute experimental Trypanosoma cruzi infection: establishing a murine model that utilises non-invasive measurements of disease parameters. Mem Inst Oswaldo Cruz 107: 211-216.

de Aluja AS 2002. Laboratory animals and official Mexican Norms (NOM-062-ZOO-1999). Gac Med Mex 138: 295-298.

de Lana M, Pinto AS, Bastrenta B, Barnabé C, Noel S, Tibayrenc M 2000. Trypanosoma cruzi: infectivity of clonal genotype infections in acute and chronic phases in mice. Exp Parasitol 96: 61-66.

Espinoza B, Rico T, Sosa S, Oaxaca E, Vizcaino-Castillo A, Caballero ML, Martinez I 2010. Mexican Trypanosoma cruzi. T. cruzi I strains with different degrees of virulence induce diverse humoral and cellular immune responses in a murine experimental infection model. J Biomed Biotechnol 2010: 890672.
Fichera LE, Albareda MC, Laucella SA, Postan M 2004. Intracellular growth of Trypanosoma cruzi in cardiac myocytes is inhibited by cytokine-induced nitric oxide release. Infect Immun 72: 359-363.

Gómez-Hernández C, Rezende-Oliveira K, Nascentes GA, Batista LR, Kappel HB, Martínez-Ibarra JA, Contreras FT, Lages-Silva E, Ramírez LE 2011. Molecular characterization of Trypanosoma cruzi Mexican strains and their behavior in the mouse experimental model. Rev Soc Bras Med Trop 44: 684-690.

Green LC, Wagner DA, Glogowski J, Skipper PL, Wishnok JS, Tannenbaum SR 1982. Analysis of nitrate, nitrite and [15N] nitrate in biological fluids. Anal Biochem 126: 131-138.

Guarner J, Bartlett J, Zaki SR, Colley DG, Grijalva MJ, Powell MR 2001. Mouse model for Chagas disease: immunohistochemical distribution of different stages of Trypanosoma cruzi in tissues throughout infection. Am J Trop Med Hyg 65: 152-158.

Guedes PM, Oliveira FS, Gutierrez FR, da Silva GK, Rodrigues GJ, Bendhack LM, Franco DW, Matta MAV, Zamboni DS, da Silva RS, Silva JS 2010. Nitric oxide donor trans-[RuCl([15]aneN)NO] as a possible therapeutic approach for Chagas disease. Br J Pharmacol 160: 270-282.

Hart DT, Vickerman K, Coombs GH 1981. A quick, simple method for purifying Leishmania mexicana amastigotes in large numbers. Parasitology 82: 345-355.

Hernández J, Carrasco J, Belloso E, Giralt M, Bluethmann H, Lee DK, Andrews GK, Hidalgo J 2000. Metallothionein induction by restraint stress: role of glucocorticoids and IL-6. Cytokine 12: 791-796.

Inoue K, Takano H, Shimada A, Satoh M 2009. Metallothionein as an anti-inflammatory mediator. Mediators Inflamm 2009: 101659.

Jacobs F, Chaussabel D, Truyens C, Leclerq V, Carlier Y, Goldman M, Vray B 1998. IL-10 up-regulates nitric oxide (NO) synthesis by lipopolysaccharide (LPS)-activated macrophages: improved control of Trypanosoma cruzi infection. Clin Exp Immunol 113: 59-64.

Jacobs F, Dubois C, Carlier Y, Goldman M 1996. Administration of anti-CD3 monoclonal antibody during experimental Chagas disease induces $\mathrm{CD}^{+}$cell-dependent lethal shock. Clin Exp Immunol 103: 233-238.

James SL 1995. Role of nitric oxide in parasitic infections. Microbiol Rev 59: 533-547.

Kang YJ 2006. Metallothionein redox cycle and function. Exp Biol Med (Maywood) 231: 1459-1467.

Katakai K, Liu J, Nakajima K, Keefer LK, Waalkes MP 2001. Nitric oxide induces metallothionein (MT) gene expression apparently by displacing zinc bound to MT. Toxicol Lett 119: 103-108.

Kim JY, Choi CY, Jeong HG 2005. Involvement of cytokines in the hepatic metallothionein expression by alpha-hederin. Planta Med 71: $743-747$

Kobayashi K, Shida R, Hasegawa T, Satoh M, Seko Y, Tohyama C, Kuroda J, Shibata N, Imura N, Himeno S 2005. Induction of hepatic metallothionein by trivalent cerium: role of interleukin-6. Biol Pharm Bull 28: 1859-1863.

Kruczek C, Gorg B, Keitel V, Bidmon HJ, Schliess F, Haussinger D 2011. Ammonia increases nitric oxide, free $\mathrm{Zn}(2+)$ and metallothionein mRNA expression in cultured rat astrocytes. Biol Chem 392: 1155-1165.

Liu J, Liu YP, Sendelbach LE, Klassen CD 1991. Endotoxin induction of hepatic metallothionein is mediated through cytokines. Toxicol Appl Pharmacol 109: 235-240. 
Majumder S, Roy S, Kaffenberger T, Wang B, Costinean S, Frankel W, Bratasz A, Kuppusamy P, Hai T, Ghoshal K, Jacob ST 2010. Loss of metallothionein predisposes mice to diethylnitrosamineinduced hepatocarcinogenesis by activating NF-kappaB target genes. Cancer Res 70: 10265-10276.

Marinho CR, Nunez-Apaza LN, Bortoluci KR, Bombeiro AL, Bucci DZ, Grisotto MG, Sardinha LR, Jorquera CE, Lira S, Lima MR, Alvarez JM 2009. Infection by the Sylvio X10/4 clone of Trypanosoma cruzi: relevance of a low-virulence model of Chagas disease. Microbes Infect 11: 1037-1045.

Martins LA, Castanho RP, de Gusmão AS, da Rosa JA 2008. Morfometria de tripomastigotas sanguíneos de Trypanosoma cruzi Chagas, 1909 (Kinetoplastidae, Trypanosomatidae). Rev Patol Reg 37: 143-150.

Mbikay M, Maiti IB, Thirion JP 1981. Cloning and sequencing of cDNA for mouse liver metallothionein-I. Biochem Biophys Res Commun 103: 825-832.

Melo RC, Brener Z 1978. Tissue tropism of different Trypanosoma cruzi strains. J Parasitol 64: 475-482.

Miles AT, Hawksworth GM, Beattie JH, Rodilla V 2000. Induction, regulation, degradation and biological significance of mammalian metallothioneins. Crit Rev Biochem Mol Biol 35: 35-70.

Millar AE, Kahn SJ 2000. Trypanosoma cruzi: the effect of nitric oxide synthesis inhibition on the CD4 T cell response to the transsialidase superfamily. Exp Parasitol 94: 84-91.

Molinero A, Carrasco J, Hernández J, Hidalgo J 1998. Effect of nitric oxide synthesis inhibition on mouse liver and brain metallothionein expression. Neurochem Int 33: 559-566.

Müller U, Sobek V, Balkow S, Holscher C, Mullbacher A, Museteanu C, Mossmann H, Simon MM 2003. Concerted action of perforin and granzymes is critical for the elimination of Trypanosoma cruzi from mouse tissues, but prevention of early host death is in addition dependent on the FasL/Fas pathway. Eur J Immunol 33: 70-78.

Nithipatikom K, Pratt PF, Campbell WB 1996. Nitro-L-arginine inteferes with the cadmium reduction of nitrate/griess reaction method of measuring nitric oxide production. Eur J Clin Chem Clin Biochem 34: 133-137.

Park L, Min D, Kim H, Park J, Choi S, Park Y 2011. The combination of metallothionein and superoxide dismutase protects pancreatic beta cells from oxidative damage. Diabetes Metab Res Rev 27: 802-808.

Pérez-Fuentes R, Guegan JF, Barnabé C, López-Colombo A, SalgadoRosas H, Torres-Rasgado E, Briones B, Romero-Díaz M, RamosJimenez J, Sánchez-Guillén MC 2003. Severity of chronic Chagas disease is associated with cytokine/antioxidant imbalance in chronically infected individuals. Int J Parasitol 33: 293-299.

Pérez-Fuentes R, López-Colombo A, Ordóñez-Toquero G, GomezAlbino I, Ramos J, Torres-Rasgado E, Salgado-Rosas H, RomeroDíaz M, Pulido-Pérez P, Sánchez-Guillén MC 2007. Correlation of the serum concentrations of tumour necrosis factor and nitric oxide with disease severity in chronic Chagas disease (American trypanosomiasis). Ann Trop Med Parasitol 101: 123-132.

Pérez-Fuentes R, Sánchez-Guillén MC, González-Alvarez C, Monteon VM, Reyes PA, Rosales-Encina JL 1998. Humoral nitric oxide levels and antibody immune response of symptomatic and indeterminate Chagas disease patients to commercial and autochthonous Trypanosoma cruzi antigen. Am J Trop Med Hyg 58: 715-720.

Pérez-Fuentes R, Torres-Rasgado E, Salgado-Rosas H, ZamoraGinez I, Sánchez-Guillén MC 2008. The anti-oxidant defence response in individuals with the indeterminate form of Chagas disease (American trypanosomiasis). Ann Trop Med Parasitol 102: 189-197.

Petering D, Krezoski S, Tabatabai N 2009. Metallothionein toxicology: metal ion trafficking and cellular protection. In S Astrid, S Helmut, KOS Roland (eds.), Metallothioneins and related chelators, Vol. 5, RSC Publishing, Cambridge, p. 353-397.

Petray P, Castaños-Velez E, Grinstein S, Orn A, Rottenberg ME 1995. Role of nitric oxide in resistance and histopathology during experimental infection with Trypanosoma cruzi. Immunol Lett 47: 121-126.

Rassi Jr A, Rassi A, Marin-Neto JA 2010. Chagas disease. Lancet 375: $1388-1402$.

Sánchez-Guillén MC, Bernabé C, Tibayrenc M, Zavala-Castro J, Totolhua J-L, Méndez-López J, González-Mejía M-E, Torres-Rasgado E, López-Colombo A, Pérez-Fuentes R 2006. Trypanosoma cruzi strains isolated from human, vector and animal reservoir in the same endemic region in Mexico and typed as T. cruzi I, discrete typing unit 1 exhibit considerable biological diversity. Mem Inst Oswaldo Cruz 101: 585-590.

Sardinha LR, Mosca T, Elias RM, do Nascimento RS, Gonçalves LA, Bucci DZ, Marinho CR, Penha-Gonçalves C, Lima MR, Alvarez JM 2010. The liver plays a major role in clearance and destruction of blood trypomastigotes in Trypanosoma cruzi chronically infected mice. PLoS Negl Trop Dis 4: e578.

Stankovic RK, Lee V, Kekic M, Harper C 2003. The expression and significance of metallothioneins in murine organs and tissues following mercury vapour exposure. Toxicol Pathol 31: 514-523.

Thirumoorthy N, Sunder AS, Kumar KM, Kumar MS, Ganesh G, Chatterjee M 2011. A review of metallothionein isoforms and their role in pathophysiology. World J Surg Oncol 9: 54.

Thornalley PJ, Vasak M 1985. Possible role for metallothionein in protection against radiation-induced oxidative stress. Kinetics and mechanism of its reaction with superoxide and hydroxyl radicals. Biochim Biophys Acta 827: 36-44.

Umekita LF, Carneiro SM, Mota I 1998. One fate of epimastigote forms of Trypanosoma cruzi injected in mice. An ultrastructural study. J Parasitol 84: 1190-1195.

Vasak M, Meloni G 2011. Chemistry and biology of mammalian metallothioneins. J Biol Inorg Chem 16: 1067-1078.

Vespa GN, Cunha FQ, Silva JS 1994. Nitric oxide is involved in control of Trypanosoma cruzi-induced parasitemia and directly kills the parasite in vitro. Infect Immun 62: 5177-5182.

Viarengo A, Burlando B, Ceratto N, Panfoli I 2000. Antioxidant role of metallothioneins: a comparative overview. Cell Mol Biol (Noisy-le-grand) 46: 407-417.

WHO - World Health Organization 2013. Chagas disease (American trypanosomiasis). Available from: who.int/mediacentre/ factsheets/fs340/en/index.html. 

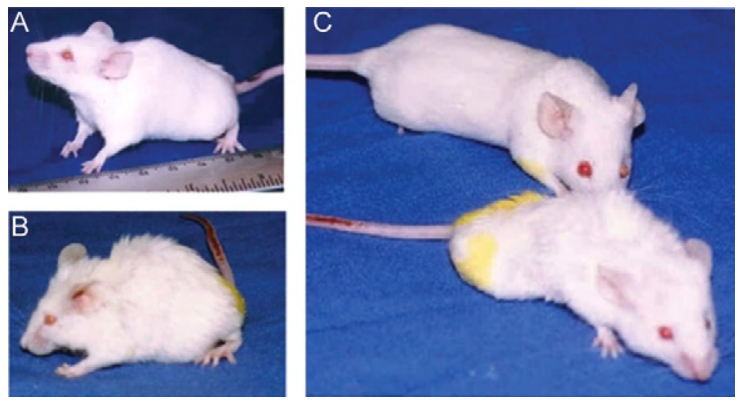

Physical characteristics of Trypanosoma cruzi RyCH1 in infected non-treated (Inf) and infected N-monomethyl-L-arginine (Inf L-NAME) treatment. A: healthy mouse showing normal posture, white brilliant fur; B: an Inf mouse showing a hunched posture and fur alterations with piloerection 75 day post-infection (p.i.); C: comparison of a lnf L-NAME (upper) and Inf (lower) mouse, showing severe paralysis of the lower extremities at 135 day p.i. 